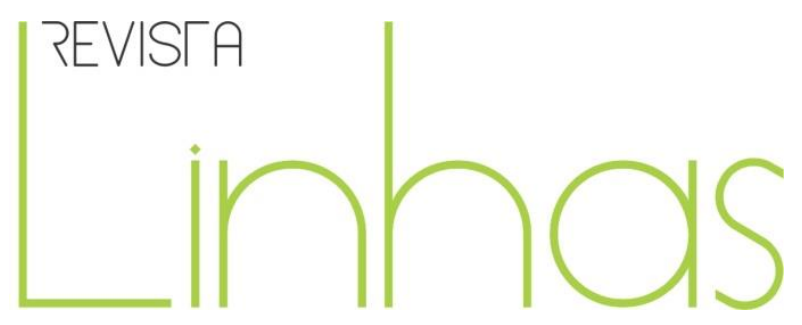

\title{
Cadernos escolares: memórias das práticas educativas do curso primário de uma escola confessional do Sul do Brasil na década de 1950
}

\begin{abstract}
Resumo
O caderno escolar tem-se revelado importante fonte para se conhecer aspectos da "caixa-preta" de uma instituição escolar, porquanto ela permite olhar as práticas através dos registros feitos pelo aluno/a e professor/a. Os cadernos, portanto, podem auxiliar na elucidação do cotidiano escolar, em diferentes épocas e espaços. Este estudo tem por objetivo desvelar aspectos das práticas educativas de uma escola confessional das Irmãs Salesianas no Sul do Brasil, na década de 1950, a partir de uma coleção de cadernos pertencentes a uma aluna que cursou o ensino primário na referida instituição. A análise dos mesmos mostra que, nos dois anos iniciais, os alunos aprendiam basicamente noções de aritmética, linguagem e religião bem como as técnicas do uso do lápis e do caderno e as habilidades da escrita. Nos cadernos dos anos subsequentes é possível observar que as aulas contemplavam o ensino dos saberes tais como os de Geografia, História, Desenho, Caligrafia e estudos mais avançados de Religião. Revelam esses materiais o recurso a exercícios rotineiros como cópias, formação de frases, ditados, questionários, resolução de contas e problemas de aritmética. O uso constante de cadernos de rascunho ou de classe e cadernos a limpo e as múltiplas tarefas para casa, revelam aspectos do percurso trilhado pela aluna em sua aprendizagem. Todavia, importa analisar o conteúdo desses materiais com precaução e em articulação com outras fontes, porquanto estas não são um testemunho pedagógico inequívoco.
\end{abstract}

Palavras-chave: Cadernos escolares. Escola confessional. Prática educativa. Ensino primário.

\author{
Ariclê Vechia \\ Universidade Tuiuti do Paraná - UTP \\ - Curitiba/PR - Brasil \\ arikele@hotmail.com \\ António Gomes Ferreira \\ Universidade de Coimbra - Portugal \\ antonio@fpce.uc.pt
}

\section{Para citar este artigo:}

VECHIA, Ariclê; FERREIRA, António Gomes. Cadernos escolares: memórias das práticas educativas do curso primário de uma escola confessional do Sul do Brasil na década de 1950. Revista Linhas. Florianópolis, v. 20, n. 44, p. 175-202, set./dez. 2019. 


\title{
School exercises books: memories of educational practices in primary school at a confessional institution in Southern Brazil during the 1950's
}

\begin{abstract}
The school notebook has been considered an important source to get to know the aspects of the school's "Black Box", since it allows us to examine the practices through the records made by the student and the teacher. The notebooks, therefore, can help understand the school routine, in different times and places. This study aims to reveal aspects of educational practices in a confessional school of Salesian Sisters in Southern Brazil, in the 1950's, from a collection of notebooks belonging to a student who attended primary school at the referred institution. These notebooks analysis shows that, in the first two years, the students learned the basics of Arithmetic, Language and Religion, as well as Writing Skills. In the notebooks of the following years, it is possible to observe that the lessons covered the instruction of subjects such as Geography, History, Drawing, Calligraphy and more advanced education in Religion. These materials unveil the adoption of routine exercises such as copies, sentence formation, dictations, questionnaires, Arithmetic problems solving. The constant use of sketchbooks and copied out notebooks, and the several homework assignments, unveil the aspects of the path travelled by the student in her learning process. However, it is essential to analyse the contents of these materials very carefully and in conjunction with other sources, since these are not an unequivocal pedagogical account.
\end{abstract}

Keywords: School exercise books. Educational practices. Confessional school. 


\section{Introdução}

A constante convocação da escola para as conversas de todos os dias não a torna mais compreensível e consistentemente entendível. O mais normal é ver o proliferar de enunciados vagos, generalizações pouco rigorosas, opiniões imprecisas e ligeiras como se a escola se confinasse a uma só concretização a uma inevitável realidade. A escola tem se concretizado por estabelecimentos muito diversificados e tem uma longa história corporificando-se em tipos de ensino distintos, condicionados pelo tempo, pelo espaço e pela tecnologia (FERREIRA, 2005). A escola é espaço de ação sujeito às condições materiais que são passíveis de ser mobilizadas. Mas a ação convocada assenta na aprendizagem da cultura escrita e isso remete para a existência de uma materialidade específica que nos permite investigar, arqueologicamente, a atividade que ela acolheu num determinado espaço/tempo.

Se desejarmos realmente compreender o que significa a atuação na escola, devemos buscar formas de chegarmos às atividades letivas porque é aí que se concretiza a intencionalidade educativa e a capacidade pedagógica que condicionará a formação. $O$ estudo histórico da educação necessita da mediação documental porque não há formas diretas de investigar a dinâmica escolar do passado. No entanto, quanto mais se retrocede no tempo maior é a dificuldade de se alcançar a vivência escolar, de se ver o desenrolar dos trabalhos, de se observar a dinâmica da relação pedagógica.

Nesse sentido, os cadernos escolares podem constituir uma importante fonte para o aumento do conhecimento sobre as práticas escolares. Os cadernos, conforme afirma Viñao (2008), são produto da cultura escolar; de uma forma determinada de organizar o trabalho em sala de aula, de ensinar e aprender, de introduzir os alunos no mundo dos saberes escolares, e dos ritmos, regras e normas escolares. Portanto, eles são uma fonte privilegiada para as pesquisas históricas que pretendem desvelar as práticas educativas de determinados períodos e em determinados espaços. Segundo Gvirtz e Larrondo (2008, p. 15), “[...] em primeiro lugar, porque os alunos os usam diariamente tanto para registrar mensagens como para desenvolver atividades e, em segundo lugar, porque tendem a permitir que sejam vistos os efeitos da interação entre professores/as e estudantes, ou seja, as tarefas escolares na sua sucessão". 
É conveniente, porém, que a sua análise não os entenda como um documento fiel da aprendizagem ou até como um registro integral das atividades do aluno. Os cadernos são muito importantes na reconstituição do percurso escolar dos alunos, mas devem ser submetidos a um olhar atento e crítico sustentado por contribições de análises provenientes de outras fontes e por um conjunto de conhecimentos de natureza política, cultural e pedagógica, que possibilite a sua compreensão na época em causa (FERREIRA; VECHIA, 2010).

Tendo consciência de que os cadernos são tão simplesmente uma das fontes importantes para melhor alcançarmos o conhecimento das atividades escolares, aqui apenas pretendemos considerar alguns aspectos em cadernos provenientes de alunos de uma escola muito relacionada a contexto sócio-histórico bastante definido. Os cadernos sobre os quais nos debruçamos permitem-nos perscrutar atividades que se inscrevem no âmbito do ensino de uma escola primária brasileira de meados do Século XX, mais especificamente, de uma cidade do interior do Estado de Santa Catarina (Brasil). Todavia, a pretensão da análise que trazemos para este artigo visa tão somente desvelar algumas práticas pedagógicas e aspectos do cotidiano vivenciados por professores e alunos de uma escola brasileira.

\section{O contexto de sua produção}

Para melhor se compreender as atividades registradas nas páginas destes cadernos, entendemos que deveríamos olhar as condições políticas e educacionais do Brasil, desde o final da chamada Era Vargas, até a aprovação da primeira lei de Diretrizes e Bases da Educação Nacional em 1961. Destaca-se que até meados dos anos 30 do século XX, o ensino primário e o secundário eram de responsabilidade de cada Estado da Federação, porém com as mudanças políticas do Governo Vargas, especialmente as estabelecidas pelo Estado Novo, as questões educacionais ficaram sob a tutela do Governo Federal. 
Dessa forma, o Decreto-Lei n. ${ }^{\circ} 8.529$ de 2 de janeiro de 1946, ${ }^{1}$ - Lei Orgânica do Ensino Primário, traçou as diretrizes para tal nivel de ensino para todo o território nacional ${ }^{2}$. Mesmo tendo sido aprovada depois do fim do Estado Novo, essa reforma fazia parte de um conjunto de reformas que fora gestado no período anterior e trazia, portanto, as marcas do regime centralizador. Segundo o referido Decreto, o ensino primário destinado às crianças dos sete aos 12 anos, foi dividido em duas categorias: a) ensino primário fundamental, com quatro anos de duração e, b) primário complementar, com um ano de duração.

O ensino primário elementar, que teria que ser frequentado por todas as crianças em idade escolar, deveria organizar-se à volta das seguintes áreas:

Leitura e linguagem oral e escrita. II. Iniciação matemática. III. Geografia e História do Brasil. IV. Conhecimentos gerais aplicados à vida social, à educação para a saúde e ao trabalho. V. Desenho e trabalhos manuais. Vl. Canto orfeônico. VII. Educação física. (DECRETO-LEI n. ${ }^{\circ} 8.529$ de 1946, Art. $7^{\circ}$ )

As diretrizes que pretendiam orientar as atividades educativas das escolas primárias revelam a influência dos princípios defendidos no "Manifesto dos Pioneiros da Educação Nova de 1932". Assim, pelo Art. 10 do referido Decreto, o ensino primário fundamental deveria atender aos seguintes princípios:

a) desenvolver-se de modo sistemático e graduado segundo os interesses naturais da infância;

b) ter como fundamento didático os interesses dos próprios discípulos;

c) apoiar-se nas realidades do ambiente em que se exerça, para que sirva à sua melhor compreensão e mais proveitosa utilização;

d) desenvolver o espirito de cooperação e o sentimento de solidariedade social;

\footnotetext{
${ }^{1}$ Até meados dos anos 30 do século XX, em virtude do sistema federativo estabelecido pela primeira Constituição Republicana de 24 de fevereiro de 1891, a educação era descentralizada. O ensino primário e 0 secundário ficavam sob a responsabilidade dos Estados da Federação que tinham o direito de legislar sobre estes níveis de ensino e o dever de mantê-los. Porém, durante o Estado Novo (1937-1945) - um regime de governo ditatorial e nacionalista, o poder foi centralizado nas mãos do Executivo Federal. Portanto, os Estados perderam o poder de legislar sobre a educação.

${ }^{2}$ A primeira Lei aprovada pelo governo central para o ensino primário foi a de 15 de outubro de 1827 , que ficou em vigor até 1946. No entanto deve-se observar que, com a descentralização da educação em 1834 e reafirmada pelo Constituição de 1891 , o ensino primário no Brasil passou por muitas reformas, porém eram reformas provinciais e posteriormente estaduais.
} 
e) revelar as tendências e aptidões dos alunos, cooperando para seu melhor aproveitamento no sentido do bem estar individual e coletivo;

f) inspirar-se, em todos os momentos, no sentimento da unidade nacional e da fraternidade humana. (DECRETO - Lei $n^{\circ} 8.529$ de 1946)

Contudo, a reforma do ensino primário, tendo sido aprovada em um contexto de transição, de retorno à normalidade democrática, permitia em seu Art. $24^{\circ}$ que os Estados fizessem adaptações da lei federal para atender às características regionais, condição esta que tinha sido negada durante o Estado Novo.

Assim, por meio do Decreto Estadual n 298 de 13 de novembro de 1946, o Estado de Santa Catarina estabeleceu a Lei Orgânica do Ensino Primário daquele Estado que ficou conhecida como a Reforma Elpídio Barbosa, em homenagem ao então diretor do Departamento de Educação do Estado. Segundo Teive e Cunha (2015), a Lei Orgânica Estadual estava em consonância com o Decreto - Lei n 8.529 de 1946, reproduzindo, com raras exceções, seus capítulos, artigos e parágrafos, o que demonstra a adesão dos dirigentes da educação pública catarinense aos princípios da Escola Nova propostos na Lei Federal. ${ }^{3}$ Para colocar em prática o estabelecido em Lei, o Departamento de Educação aprovou o "Regulamento para os Estabelecimentos do Ensino Primário" pelo Decreto n 3.735 de 17 de dezembro de 1946, que estabelecia, em minúcias, como deveria ser o funcionamento das escolas de ensino primário.

Apesar de ter sido votada uma nova constituição em setembro de 1946 que restabeleceu os princípios democráticos e estabeleceu novos principios e finalidades para a Educação, a Lei Orgânica do Ensino Primário ficou em vigor por 15 anos, pois somente em 1961 foi aprovada a Lei 4024/61, - a primeira Lei de Diretrizes e Bases da Educação Nacional (LDB).

Durante a tramitação da proposta da LDB, isto é, de 1948 a 1961, ocorreram muitos debates e propostas de renovação educacional para o ensino primário, visando atender

\footnotetext{
${ }^{3}$ Durante o governo Vargas (1937 a 1945), os princípios da Escola Nova foram questionados; ocorreram intensos debates e enfrentamentos entre liberais, defensores do escolanovismo, católicos de posição mais conservadora e o governo. Segundo Francisco Campos, o ideólogo do Estado Novo (1937-1945), a educação deveria ser um instrumento de propagação da ideologia do Estado entre as crianças. Campos criticava o sistema educativo "de fundo liberal", até aquela data, adotado no Brasil e os princípios defendidos pela Escola Nova. Segundo ele, esta educação não tinha uma finalidade definida, era como se "estivéssemos preparando uma equipe de aventureiros" (VECHIA; FERREIRA, 2016).
} 
ao aumento da demanda por educação decorrente das mudanças socioeconômicas que se verificavam no país, tais como a industrialização e a crescente urbanização. Um novo conceito de escola primária foi debatido e urgia a renovação dos programas e métodos de ensino. Discutia-se também a necessidade de adoção de novos métodos de alfabetização, a introdução do ensino da Matemática Moderna e a integração de conteúdos de várias disciplinas. Os cadernos que analisamos foram produzidos durante o período de tramitação da primeira LDB, marcado por instabilidades políticas e educacionais, eivado de debates em torno de propostas educacionais para o ensino primário, mas de muita instabilidade e sem que alguma decisão relevante fosse tomada.

\section{O que nos revelam os cadernos da década de 1950}

O conjunto de 25 cadernos analisado neste estudo faz parte uma coleção de 33 cadernos pertencentes a uma aluna que cursou o ensino primário de 1955 a $1958^{4}$, em uma escola confessional de uma cidade do interior de Santa Catarina, no Sul do Brasil. Esse Municipio foi colonizado por imigrantes europeus, em sua maioria, italianos que, por serem em maior número, acabaram por imprimir certas características ao mesmo. 0 colégio frequentado pela aluna pertence à Ordem das Irmãs Salesianas da Congregação das Filhas de Maria Auxiliadora que, em 1928 fundou um colégio naquela região com a finalidade de ofertar educação escolar para meninas e meninos e colaborar, com a paróquia, na evangelização e promoção da educação, principalmente para os descendentes de imigrantes italianos. Contudo, a formação cristã das meninas era, sem dúvida, a razão principal da atividade educativa do Colégio.

Como seria de prever, os cadernos, embora pertencentes à mesma aluna, divergem uns dos outros por várias razões. O primeiro subconjunto de cadernos analisados é datado do ano de 1955 e contém registros sobre as práticas pedagógicas referentes ao primeiro ano do ensino primário. Eles colocam-nos, portanto claramente diante das primeiras aprendizagens da aluna. Os registros mostram que há mais do que o exercitar cognitivo ou a memorização de conteúdos. Por eles se vê que a aluna teve que

\footnotetext{
${ }^{4}$ Os cadernos do primeiro e do segundo ano são do tipo brochura, possuem uma capa de cartolina, bem fina, sendo que cada um contém cerca de 50 páginas. Alguns deles estão encapados com papel encorpado no tom bege, outros devem ter perdido suas capas no transcorrer do tempo.
} 
aprender as técnicas de escrita e dominar o uso de materiais como o lápis e a borracha, bem como atender ao espaço do caderno, desenvolvendo uma motricidade enquanto mecanicamente memorizava conteúdos que iam sendo disponibilizados. O primeiro exercício exemplificava bem uma pedagogia de repetição. A professora escreveu o nome da aluna na primeira linha da página e esta teve que copiá-lo ao longo de quatro páginas. A primeira e a segunda páginas nos revelam as dificuldades que aluna tinha para usar o lápis e para escrever. Na terceira e na quarta páginas de cópias, a letra já se revela mais legível, o que permite constatar a gradativa aquisição da habilidade da escrita.

Sem surpresas, surgem logo no início, exercícios relacionados com a matemática. Lá se registram atividades com que se pretendia alcançar a aprendizagem dos números. Por exemplo, a professora escrevia, na primeira linha, um determinado número por diversas vezes, separado por um traço, para que a aluna copiasse dezenas e dezenas de vezes o mesmo número, conforme figura 1.

Figura 1. A aprendizagem da escrita dos números

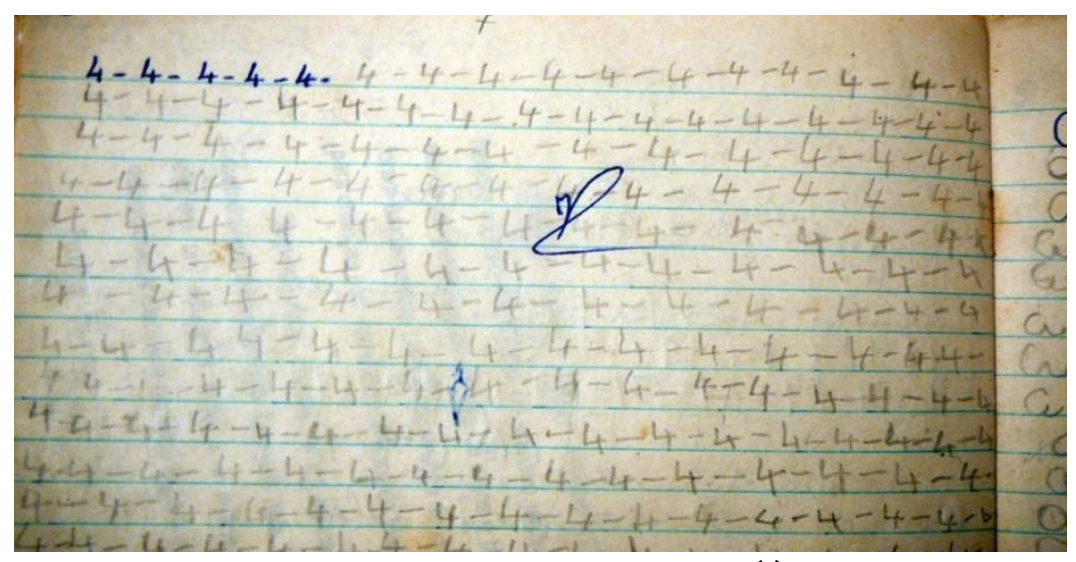

Fonte: Foto de A. Vechia, 2019 - Caderno de Classe (I) do ano de 1955.

A aluna prosseguiu na repetição, preenchendo a página com o número quatro. Aqui, o propósito do exercício não era a memorização, mas a aquisição da habilidade de escrita dos números e do uso do espaço das folhas do caderno, visto que tinha que tentar escrever um algarismo abaixo do outro. Tendo a página 20 linhas, foi necessário escrever 280 vezes o mesmo número.

Dos cadernos podemos inferir a lógica da alfabetização que orientava o ensino em causa. A alfabetização envolve o domínio do código de escrita e de leitura, mas este pode 
ser alcançado por diferentes modos. A aprendizagem da escrita revela-se de maior complexidade e nem sempre isso é devidamente equacionado. Não é indiferente o tipo de material usado bem como a familiaridade com ele por parte dos alunos. A alfabetização em geral também está ligada a aspectos de disciplina, de organização, de comunicação e estes se definem por princípios pedagógicos mais ou menos explícitos.

Alguns cadernos, utilizados no segundo semestre, revelam que a professora procurava passar uma lógica de organização estética no seu uso, pois além de possuírem uma margem impressa que deveria ser respeitada, as lições se iniciam com a escrita de um cabeçalho contendo o nome da escola e da cidade bem como a data e o nome da aluna. O ensino da escrita é complexo, tem normas próprias e está muito dependente dos materiais utilizados.

O caderno é um suporte cada vez mais utilizado ao longo do século XX para o registro das atividades escritas dos/as alunos/as que frequentavam a escola elementar e, por isso, constitui-se como uma importante fonte das características do ensino/aprendizagem mais valorizadas na escola que enquadrou a sua utilização. Ele pode permitir, designadamente, ver como os/as alunos/as aprendem a dominar o espaço gráfico que é determinado por normas que dispõem sobre a forma e a ordem do uso das páginas. Existe, portanto, conforme destaca Viñao (2008), um código de apresentação para os registros realizados nos cadernos: uso do cabeçalho da tarefa diária, título de cada atividade, respeito às margens, tamanho da letra, além de outras. Além do efeito estético, a prática dessas normas de disposição gráfica, visava também servir uma pedagogia reguladora e disciplinar. A escrita dos cadernos revela a "criação de hábitos", a incorporação de valores e normas de conduta, a relação entre a forma e o conteúdo e entre docente e aluno/a.

Os cadernos estudados mostram uma intencionalidade definida pela professora, que segue uma lógica didática na qual o treino era relevante. Para conseguir que a aluna fizesse os registros seguindo as normas, presume-se que a professora teve que propiciar inúmeros exercícios para o desenvolvimento de habilidades motoras desde o modo como segurar o lápis, o desenhar as letras, escrever em linha reta até organizar os grupos de sílabas e palavras, etc. Os cadernos escolares, muitas vezes, oferecem apenas indícios sobre um conjunto de práticas vivenciadas em sala de aula. Conforme Ferreira; Vechia 
(2010) e Rios; Fischer (2017) apontam, os limites explicativos inerentes aos cadernos estão efetivamente traçados, mesmo quando as questões que se quer analisar referem-se às práticas dos alunos, às suas produções ou, de modo mais geral, às suas ações em ambiente escolar, mas escapam ao universo da escrita.

Tendo sido razoavelmente adquiridas as habilidades da escrita e as noções básicas da disposição gráfica exigidas no uso das páginas, as atividades passaram a incluir cópias de frases que a professora escrevia no caderno progredindo para a cópia de pequenos textos. Analisando-se os registros anteriormente mencionados, constatamos que os textos eram copiados da Cartilha Lalau, Lili e o Lôbo, de autoria de Rafael Grisi ${ }^{5}$, que foi a adotada pela escola. A referida Cartilha foi elaborada segundo o Método Analítico, uma das inovações educacionais discutidas na década de 1950 e adotadas por várias escolas primárias do país. Segundo esse método, a alfabetização deveria começar pela: Setenciação: domínio das frases completas, apresentadas e reconhecidas no seu conjunto gráfico; Palavração: decomposição das sentenças em palavras; Silabação: decomposição das palavras em sílabas e Soletração: decomposição das sílabas em letras (GRISI, 1951).

De qualquer modo, o que se vê dos registros é a primazia de um didatismo infantil. Sem excluirmos a possibilidade de outros exercícios mais expressivos e contextualizados, tendemos a considerar que se seguia mais a técnica que o espírito do método de iniciação à leitura. Um dos textos copiados era o seguinte:

\author{
O menino se chama Lalau \\ A menina se chama Lili \\ Lalau tem um cavalo \\ Lili tem uma boneca \\ O Cavalo é de pano. (CADERNO DE CLASSE II, 1955)
}

A escrita consistia na cópia de frases pouco expressivas que repetiam algumas palavras com o intuito de serem memorizadas. Com o transcorrer do tempo, os textos

\footnotetext{
${ }^{5}$ Rafael Grisi nasceu em 1909 em São Paulo. Atuou, como professor de Psicologia Educacional, História da Educação, Pedagogia, Filosofia Educacional e Didática -, em Escolas Normais e Faculdades de Filosofia Paulistas. Autor de livros e vários artigos sobre os métodos de alfabetização. Nos anos de 1950, escreveu a cartilha Lalau, Lili e o Lôbo e uma série de livros de leitura para o curso primário.
} 
copiados tornavam-se gradativamente mais complexos, como se pode ver no seguinte exemplo:

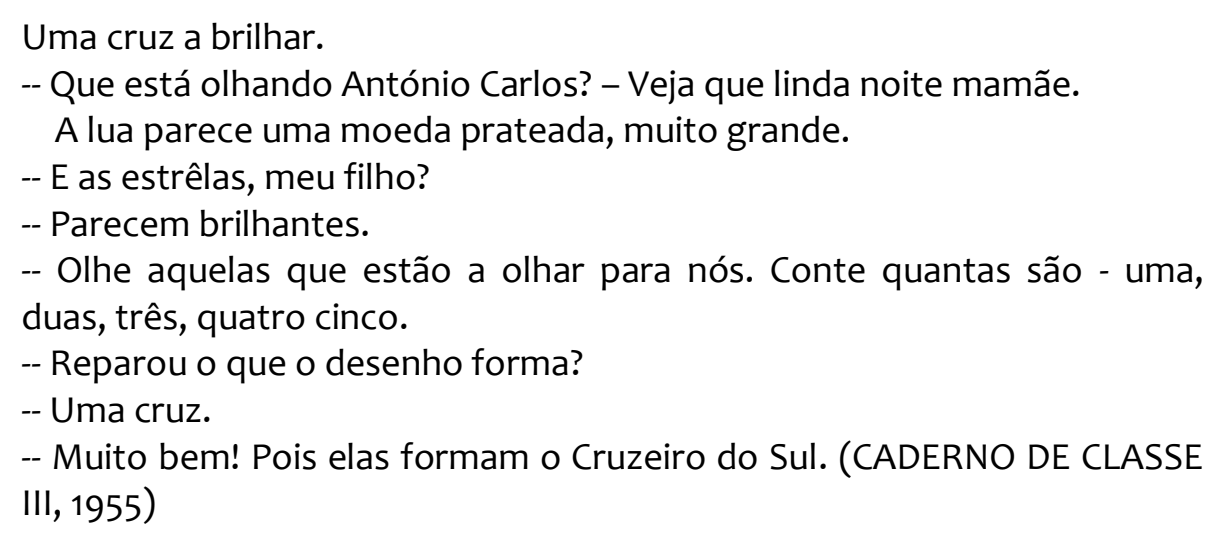

Comprende-se um esforço para se proporcionar uma pedagogia mais intuitiva. Há apelo ao sentimento e aos sentidos. Mas a mecânica dos exercícios de cópia entremeados com muitos ditados de sílabas, de palavras e de frases deixa ver uma rotina disciplinadora, marcada por uma lógica didática baseada na repetição.

Ditado.

Ga, go, gi, ge, gelo, geada.

Gula, galo, gaveta, gila.

Gesso, geleia, gelatina.

Gago, guloso, agulha, giboia

Mugido, tigela, geleira, ginete, geme

Generoso, liga, girafa, geladeira [...]

O rato foge de medo.

Eu já vi uma girafa

A fera fugiu da giboia (sic). (CADERNO DE CLASSE III, 1955)

Quando uma sílaba ainda desconhecida era exigida nos Ditados, emergia naturalmente uma dificuldade e, via de regra, a aluna cometia erros, pois o método não previa o ensino prévio das letras e da formação de sílabas. Como exemplo disso, podemos observar na figura 2 um Ditado que revela que a aluna não dominava o dígrafo consonantal - glo. 
Figura 2. Exercício de classe - Ditado

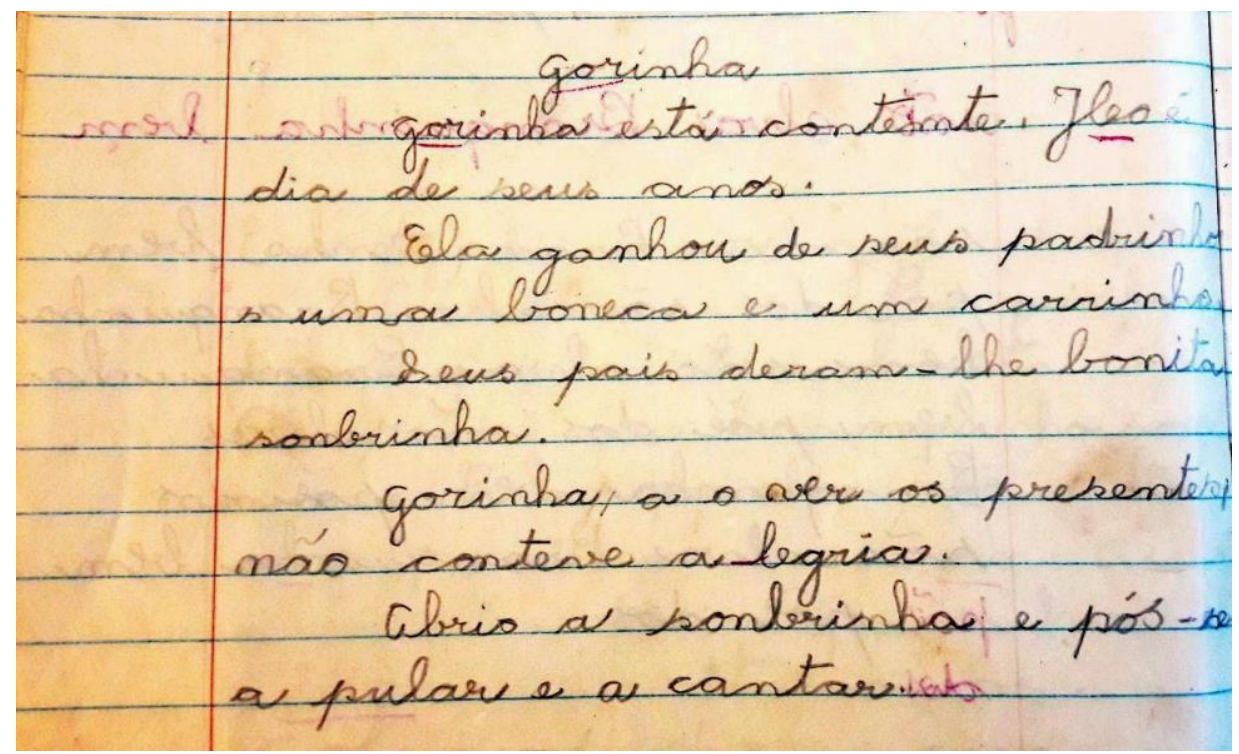

Fonte: Foto de A. Vechia, 2019 - Caderno de Classe (II) do ano de 1955.

Os exercícios de cópia revelam que, muito embora o método previsse a decomposição das palavras conhecidas em sílabas, a professora nem sempre utilizava essa prática ${ }^{6}$. Ela insistia em escrever de forma correta as palavras que a aluna tinha errado para que esta repetisse diversas vezes a sua escrita, tais como: "Glorinha, Hoje, alegria, sombrinha", conforme figura 3.

Figura 3. Treino da escrita correta das palavras

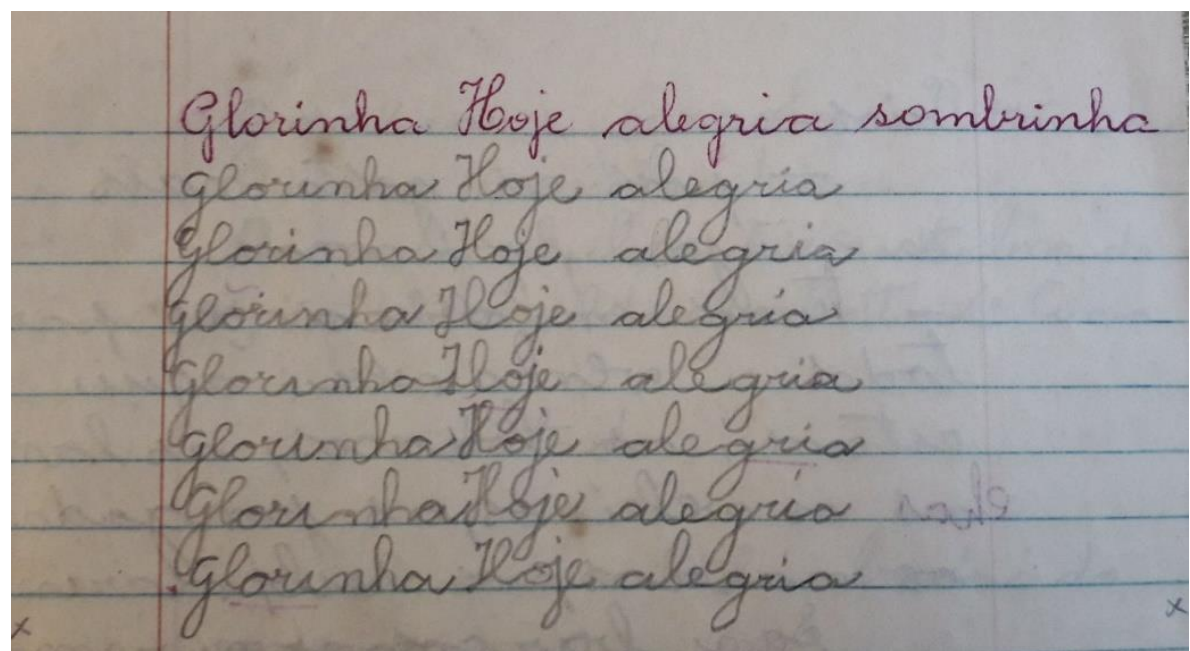

Fonte: Foto de A. Vechia, 2019 - Caderno de classe do primeiro semestre do ano de 1955.

\footnotetext{
${ }^{6}$ Não encontramos nenhum registro anterior ou posterior ao Ditado que trabalhasse com a divisão das palavras em silabas. Alguns exercícios de divisão em silabas foram encontrados, mas utilizando palavras ainda desconhecidas.
} 
Numa primeira apreciação, temos um exagero de repetições e pouco cuidado com a compreensão dos problemas em causa. Todavia, será conveniente proceder a uma análise mais sistemática e enquadrada, considerando outros elementos e informações para podermos ser mais categóricos. De um ponto de vista descritivo, vamos vendo páginas escritas por uma aluna onde estão registrados exercícios escolares próprios de um primeiro ano. A sequência traduz um percurso de aprendizagem a partir de uma forma de ensino.

Um dos cadernos contém os registros das tarefas realizadas durante o segundo semestre que incluíam: cópias e ditados sobre temas diversos, criação de histórias à vista de figuras e exercícios de sinônimos e antônimos. As tarefas de Aritmética eram compostas de ditados de algarismos arábicos, de escrita dos números, por exemplo: de 1 a 29 e de contas de somar de um e de dois algarismos.

Outro caderno era destinado às provas semestrais e mensais das disciplinas: Linguagem, Aritmética e Religião. As provas de Linguagem exigiam a realização de cópias, ditados e exercícios de separação em sílabas. A prova de Religião verificava os conteúdos do Catecismo para o primeiro ano primário. A verificação da aprendizagem era feita por meio de perguntas e respostas, como, pode-se observar na figura 4 e em nota de rodapé .

\footnotetext{
7 Prova Mensal de Religião:

$1^{\circ}$. Jesus quer bem os meninos?

Poriso os meninos bons querem muito bem a Jesus (sic). $2^{\circ}$. Qual é o livro que nos ensina a querer bem a Jesus?O livro que nos ensina a querer bem a é o catecismo (sic). $3^{\circ}$. Que é que nos lembra o Sinal da Cruz? Faz lembrar que Jesus morreu pornôs (sic). $4^{\circ}$. Qual é a oração que Jesus nos ensinou? É o padre nosso (sic). $5^{\circ}$. Com que oração você cumprimento Nossa Senhora? (sic). Com a ave maria. (sic) (Cadernos, 1955).
} 
Figura 4. Prova mensal de Religião

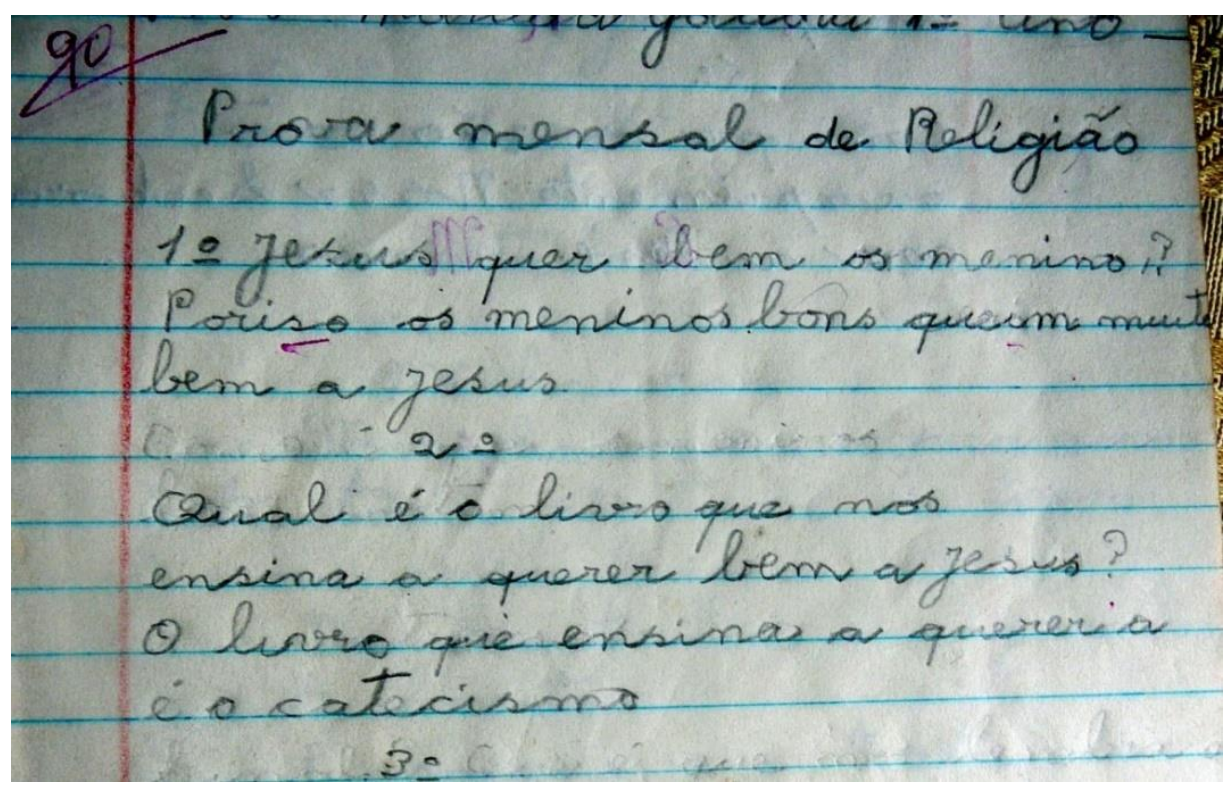

Fonte: Foto de A. Vechia, 2019 - Cadernos de classe do segundo semestre de 1955.

Como se sabe, as atividades desenvolvidas em sala de aula não se circunscreviam apenas a exercícios escritos. Elas seguramente contemplavam outras dinâmicas além das que podemos ver nos cadernos. Algumas até se podem depreender dos registros deixados nos cadernos, como o exercício da leitura ou explicações orais pela professora sobre vários aspectos. A escrita, contudo, sistematiza e organiza melhor o conhecimento mais valorizado. Viñao (2008) destaca esse aspecto quando afirma que os cadernos silenciam sobre as intervenções orais ou gestuais do professor e dos alunos, sobre o ambiente ou clima da sala de aula, sobre as atividades que não deixam pistas escritas ou de outro tipo, como os exercícios de leitura e todo o mundo do oral.

O conjunto de cadernos do segundo ano, entre eles, cadernos de borrão, a limpo, de exercício, de tarefas e de provas revela uma atividade pedagógica bastante intensa e centrada nos exercícios escritos. Os registros desses cadernos permitem ver que a importância dada às matérias de Linguagem, Aritmética e Religião, existentes no primeiro ano, fora alargada às Noções de História e de Geografia.

Um dos cadernos identificados, como sendo de rascunho, na realidade tem registrado em suas páginas as tarefas a serem realizadas em casa e incluíam os conteúdos de todas as matérias estudadas no segundo ano. $O$ ensino da Linguagem era muito enfatizado, as tarefas solicitadas compreendiam: cópias de trechos de textos, análise 
sintática, o aumentativo e diminutivo das palavras, o passar do masculino para o feminino, formar sentenças, separar em sílabas e a produção de pequenos textos (CADERNO DE RASCUNHO, 1956).

Os textos das cópias eram sobre temas variados: A Escola, Nossa Bandeira, A pobreza não é desdouro, Quem sou eu? O correio, A casa-grande, A muçurana, São Francisco de Assis, entre outros (CADERNO DE EXERCíCIOS, 1956). Tudo indica que se tratava de atividade complementar à de leitura, porquanto os textos foram retirados do livro Infância de autoria de Henrique Ricchetti, publicado em 1952. É visível a intenção de intervir no sentimento das crianças procurando que estas interiorizassem ideias caras à sociedade brasileira de então. Dentre os vários textos estudados, destacamos aqui um exercício de cópia sob o título Nossa Bandeira, onde essa intencionalidade estava bem presente:

\section{Cópia.}

Nossa bandeira é linda!

É o símbolo de nossa Pátria.

Suas cores resumem, a nossos olhos, toda a sua grandeza!

O "verde" é a cor dos nossos mares e de nossas florestas!

O "azul" côr do céu infinito que nos cobre, do céu em que aparecem em forma de cruz, como para nos abençoar as estrêlas do Cruzeiro (sic). (CADERNO DE EXERCÍCIO, 1956)

Segundo Ricchetti (1952), o livro tinha por finalidade aprimorar a aprendizagem da leitura por meio de narrativas de cenas familiares e comuns à vida infantil e de contos. Sugere que cada assunto poderia ser transformado pela professora em "um centro de interesse", de acordo com as modernas tendências da Didática. Ao final de cada capítulo sugeria atividades que poderiam ser exploradas para o ensino de História, Geografia, Educação Moral e Cívica. Mas, observando bem os cadernos, tudo leva a crer que o livro não era tão explorado como o pretendido pelo autor, que propunha práticas embasadas nos princípios da Escola Nova. Em geral, os exercícios eram propostos pela professora visando à memorização e o treino da escrita e raramente foram aproveitados os exercícios sugeridos no livro. Este podia ter o seu interesse pelo teor dos textos a utilizar como lições de leitura, mas concorria com outros conteúdos e com diferentes entendimentos de ensino. 
Não há dúvida de que a análise dos cadernos escolares, conforme salientou Viñao (2008), possibilita a elucidação sobre como acontece a transmissão e a inculcação de ideologias e valores no meio escolar. Nesse aspecto, eles tendem mesmo a ser mais interressantes que os livros didáticos, porque permitem uma aproximação mais fidedigna à realidade do ensino e às práticas escolares. Ora, os cadernos analisados não deixam dúvidas sobre a relevância dada à inculcação de valores religiosos. O que nos chama novamente à atenção é o número de tarefas de Religião que deviam ser realizadas em casa. Elas eram quase que diárias e estavam embasadas no catecismo adotado para o segundo ano primário - O Teu Catecismo, publicado pela Livraria da Doutrina Cristã (LDC) e divulgado pelas Livrarias Salesianas do Brasil. Ora, este catecismo era composto de 30 lições e incluía ainda uma seção de cantos religiosos e outra de perguntas e respostas sugeridas para verificação da aquisição do conteúdo das lições (CADERNO DE EXERCÍCIOS, 1956).

Analisando o terceiro conjunto de cadernos, referente ao terceiro e quarto anos, constatamos que houve, como não podia deixar de ser, uma ampliação dos saberes ensinados. Às matérias já presentes no segundo ano, foram acrescentados os estudos de Desenho Geométrico e a prática da Caligrafia. Depois de ter adquirido razoável domínio do uso do lápis, da caneta tinteiro e do caderno, no terceiro ano, com vistas à melhoria da habilidade de escrita, a aluna passou a realizar exercícios de Caligrafia. Os registros feitos em um caderno, específico para tal finalidade, revelam que ela tinha que completar páginas inteiras, copiando o nome da escola, seu próprio nome e frases diversas, bem como, treinar a escrita de letras maiúsculas em estilo simples e outro mais rebuscado, sempre seguindo o modelo proposto pela professora. A figura 5 ilustra uma das tarefas. 


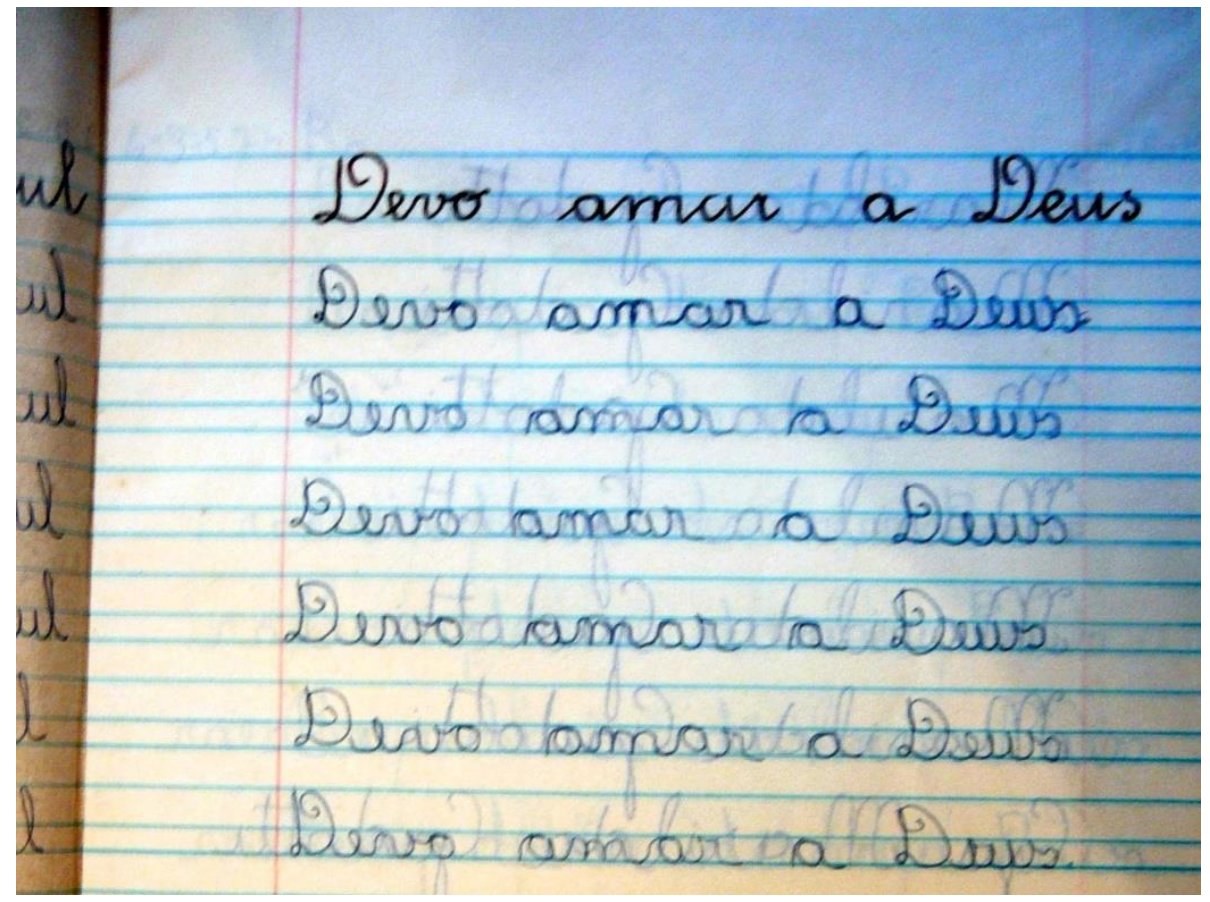

Fonte: Foto de A. Vechia, 2019 - Caderno de Caligrafia do terceiro ano primário, 1957.

Segundo Rogerio Fernandes (2008), o processo de ensino-aprendizagem da caligrafia implicava uma vigilância constante do professor sobre o aluno. Contudo, não é provável que a aluna seguisse todas as exigências da aprendizagem caligráfica, dominando, como sugere o mencionado autor, as convenientes posturas corporais da cabeça, cotovelos, antebraços, tronco, pernas e pés, assim como o modo de manipular uma caneta antes de iniciar os exercícios de escrita. Por exemplo, será que a cabeça não ficava inclinada nem para a direita nem para a esquerda, apenas um pouco para frente, de modo a ficar aproximadamente 30 centímetros de distância da folha de escrita? Será que segurava a caneta entre os três primeiros dedos: indicador, médio e polegar, sem apertar muito para não cansar? Uma coisa é certa, os registros nos cadernos nos revelam que o domínio de uma escrita bem elaborada não era uma das finalidades principais do ensino primário, haja vista que o número de exercícios de Caligrafia era pequeno, se comparado com a de outros tipos de exercícios, nomeadamente os de linguagem.

Um dos cadernos, identificado como "Caderno a limpo", foi utilizado para registro dos conteúdos de: Conhecimentos Gerais, História e Geografia. Nesse caderno registavase por certo o resultado de trabalho anterior e dá expressão ao alcance do ensino 
pretendido em matérias que deveriam constituir a formação de uma pessoa escolarizada. A parte destinada aos Conhecimentos Gerais revela que nestes se contemplavam noções sobre alimentação, meios de comunicação, questões de saúde e higiene, entre outros. Por exemplo, a alimentação era abordada em textos, copiados de um livro, onde se destacam os benefícios de cada tipo de alimento: frutas, verduras, legumes, laticínios, etc., enquanto os relativos aos meios de comunicação abordam temas como: aeroplano telégrafo, telefone, trem de ferro, bicicleta, bonde, automóvel, além de outros (CADERNO A LIMPO, 1957).

Os textos são simples, mas pretendem assegurar uma formação geral capaz de assegurar o mínimo cultural indispensável a quem deveria integrar uma mão de obra necessária ao desenvolvimento do país e da região. Nesse sentido, não surpreende que fosse abordada a higiene corporal e o vestuário. Em uma das lições, por exemplo, explicase a função da pele para o corpo humano e a necessidade de mantê-la limpa, bem como o cuidado com o vestuário de forma bastante singela:

A pele é a parte do corpo que cobre os músculos. É cheia de buraquinhos. [...]Se não tomarmos banho sempre os poros da pele ficam fechados e isto faz mal para as pessoas, principalmente no calor [...]. Não sendo possível todos os dias pelo menos 2 ou 3 vezes por semana as pessoas devem tomar banho. Devemos lavar o rosto as orelhas o pescoço e as mãos todos os dias. Além do asseio do corpo é necessário haver asseio do vestuário. Este deve ser trocado 2 ou 3 vezes por semana: a roupa de baixo e a de cima devem ser bem limpas lavadas e escovadas (sic). (CADERNO A LIMPO, 1957)

Pelos cadernos analisados vemos que o ensino da Geografia se fazia do mais próximo para o mais afastado. Assim, o estudo começava pelo conhecimento do Município: os bairros, os acidentes geográficos, as estradas, a população, o comércio e a indústria e os limites; a seguir vinha o estudo da Geografia Física de Santa Catarina: Portos, Ilhas, Cabos, Estreito e outros. Para o estudo da população, da produção e das vias de comunicação do Estado, eram indicadas as páginas a serem estudadas diretamente do livro: Vamos Estudar - $3^{\text {a }}$ série primária, de autoria de Theobaldo Miranda Santos. As obras deste autor eram indicadas e adotadas em vários estados do país, porém existiam volumes específicos para cada região. 
Os estudos de História também começam pela História do Município e a organização política do mesmo, na sequência, era estudada a História de Santa Catarina e, posteriormente, aspectos da História do Brasil. Segundo um dos cadernos designado de "rascunho", as lições de História do Brasil incluíam os seguintes pontos: João Ramalho, Descobrimento do Brasil, Tomé de Sousa, Tiradentes, Libertação dos Escravos, as Bandeiras além de outros. Esses conteúdos deveriam ser estudados também nos livros indicados, pois nos registros das Tarefas para Casa, sempre aparece a indicação das páginas do livro a serem estudadas. Porém, observa-se que o ensino era dado em tópicos ou temas que se apresentavam, em geral, em ordem cronológica, mas não havia conexão entre uma lição e outra, mais parecendo uma coleção de contos diversos.

As anotações feitas em um dos cadernos dedicados ao segundo semestre revelam que os estudos de Conhecimentos Gerais foram retomados. O primeiro tópico tratava de identificar, pelos nomes, as autoridades do país. A seguir, identificava e conceituava os órgãos responsáveis pelos serviços públicos e os poderes da República. As lições deveriam ser estudadas, no livro Vamos Estudar entre elas as que abordavam: Os Símbolos Nacionais, As eleições e Noções de Autoridade.

Os temas de Ciências Físicas e Biológicas entre eles: a respiração, o ar, o calor, os cuidados com a água, alimentação e etc. deveriam ser estudados no livro A Infância Brasileira, terceira série de Ariosto Espinheira. A edição do livro indicado era de meados de 1952, mas o mesmo estava de acordo com a legislação de 1946, que permanecia em vigor, pois em uma das páginas iniciais do mesmo, está impresso o número de autorização para seu uso, concedido pelo Ministério da Educação e Saúde. Esta exigência foi colocada em vigor durante o Estado Novo.

Nos Cadernos de Tarefas, além de registros das tarefas de Linguagem e de Aritmética $^{8}$, destacam-se as tarefas de Religião, que continuavam sendo quase que diárias, assim como acontecia nos anos anteriores, e geralmente, remetiam ao estudo dos conteúdos do catecismo Luz do Céu da Livraria Editora Salesiana para o $3^{\circ}$ ano. Os registros revelam que o Catecismo era estudado por inteiro. Além do estudo e dos exercícios recomendados, os conteúdos eram avaliados em provas mensais.

\footnotetext{
${ }^{8}$ Análises mais aprofundadas sobre o ensino da Aritmética não constam deste estudo.
} 
Os cadernos referentes ao quarto ano primário nos revelam que aos conteúdos já estudados no terceiro ano, foram acrescentados os de Ciências como matéria autônoma. Os saberes ensinados e as práticas pedagógicas adotadas eram muito semelhantes aos do terceiro ano, ainda que tivessem algum aprofundamento em quase todas as matérias. Os cadernos de Exercícios e de Provas de Linguagem revelam que eram exigidos conhecimentos sobre análise sintática, ditados de palavras e de textos, reprodução de contos, composição à vista de uma figura, aspectos diversos da gramática: acentuação, sinônimos, antônimos, aumentativos, superlativos, tempos dos verbos, advérbios e pronomes.

Os conteúdos de História do Brasil, registrados em um dos cadernos, perfaziam um total de 60 'pontos' ou lições, que deveriam ser estudados em livros indicados. Abrangia o estudo do mundo antigo, os descobrimentos portugueses, o Brasil Colônia, o Brasil Imperial até a Proclamação da República; naturalmente, era uma História baseada em datas e fatos e a verificação da aprendizagem, via de regra, era feita usando Questionários. Já os estudos de Geografia, tratavam da geografia física do Brasil: os picos, as montanhas, os principais rios e seus afluentes e, da geografia física geral: os oceanos, os picos e as montanhas, os movimentos terrestres, além de outros.

Os estudos de Ciências estavam assentados no conhecimento do corpo humano. Foram estudados, com algum detalhamento os órgãos dos sentidos, os órgãos internos e os membros superiores e inferiores, dando aos alunos uma noção geral do funcionamento de cada tipo de membros ou órgãos. Por sua vez, os conteúdos e os exercícios de matemática, eram apropriados para a utilização no comércio, na indústria e em outras profissões e serviços que exigissem conhecimentos de cálculos diversos, frações, pesos e medidas, percentagem, lucro, frações e resolução de problemas.

As Tarefas de Religião eram sempre as primeiras da lista de trabalhos das diversas disciplinas indicadas. Continuavam sendo quase que diárias e geralmente remetiam ao estudo dos conteúdos do catecismo Luz do Céu da Livraria Editora Salesiana. Assim como ocorria nos anos anteriores, o Catecismo era estudado por inteiro e o seu conteúdo era avaliado nas provas mensais.

O caderno sendo, antes de tudo, um espaço de registro dos saberes ensinados, bem como das práticas escolares adotadas fornece também, aos historiadores, 
elementos para análises sobre a interação entre professores e alunos, principalmente usando o expediente da avaliação sobre o progresso e as dificuldades dos alunos (Chartier, 2002, 2007). Os cadernos analisados revelam que a partir do $1^{\circ}$ ano, mas de forma mais acentuada a partir do $3^{\circ}$ ano, as tarefas realizadas em sala de aula ou em casa, realizadas nos cadernos de rascunho ou passadas a limpo em cadernos específicos, na maioria das vezes eram supervisionadas pela professora que deixava a sua marca de participação naquele processo escrevendo "Visto" com caneta de tinta vermelha, na margem esquerda ou em local destacado das páginas. Algumas tarefas realizadas mais ao final do $3^{\circ}$ ano começaram a ser avaliadas uma vez que a professora, além de dar o "Visto", corrigia as cópias, as redações, os cálculos aritméticos, e outras tarefas, marcando as questões com um "C" quando corretas e com "ER" quando erradas. A localização e a disposição das marcas de correção fazem parte de um conjunto de dispositivos pertencentes ao sistema escolar e, neste sentido, delimitam as funções e os papéis dos indivíduos envolvidos nessa atividade. Esta diferenciação da cor, utilizada na correção, pode indicar traços de controle, das relações de força e poder que se sustentam em determinado tipo de saber. Por meio da correção, manifesta-se o poder do saber que inclui ou exclui a produção do aluno (LOPES, 2008).

Nos cadernos do $4^{\circ}$ ano essa prática tornou-se constante: as tarefas realizadas com caneta tinteiro nos cadernos "a limpo" e as provas realizadas em cadernos específicos para tal finalidade, recebiam um "Visto", eram corrigidas e recebiam uma nota, sendo que todas estas anotações eram feitas com caneta tinteiro na cor vermelha, conforme se pode ver na figura 6 . 
Figura 6. As marcas de correção em uma prova de Aritmética

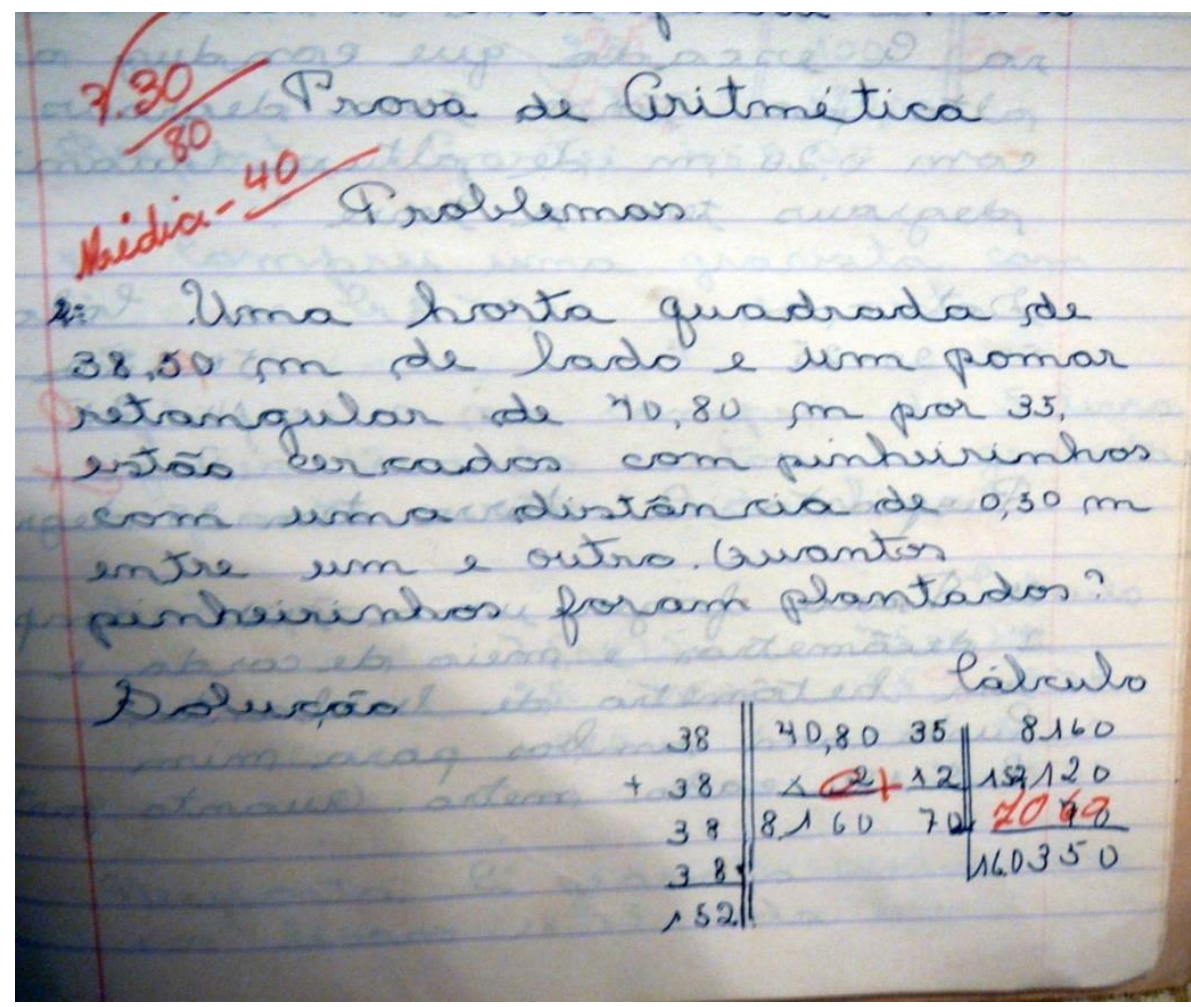

Fonte: Foto de A. Vechia, 2019 - Cadernos de provas do ano de 1958.

Desde sua origem, os cadernos estiveram associados ao controle nas instituições educacionais. As cores utilizadas na escrita são convencionadas socialmente, podendo produzir determinados sentimentos. A cor vermelha, em geral, associa-se ao cuidado, à vigilância sobre as atividades realizadas por todos os alunos, assinalando o posicionamento hierárquico das relações institucionais (SANTOS; SOUZA, 2005; LOPES, 2008).

Essa prática permitia que a professora analisasse se as tarefas foram bem executadas, qual o progresso das alunas, enfim, que detectasse suas deficiências na aprendizagem de maneira geral. Os cadernos podem atuar também na relação entre a escola, professores e os pais de alunos. São materiais que transitam diariamente entre a escola e a casa dos alunos, podendo levar e trazer informações (SANTOS; SOUZA, 2005). Os 'Cadernos de Provas' e os 'Cadernos de Tarefas' do $4^{\circ}$ ano eram também enviados mensalmente para os pais. Esses cadernos eram assinados pelo pai da aluna ou pelo pai e pela mãe. As assinaturas significavam que eles estavam cientes, ou pelo menos tiveram a oportunidade de se inteirar do progresso ou das dificuldades da filha. Os cadernos 
serviam também para que a professora enviasse mensagens aos pais, geralmente relacionadas às dificuldades de aprendizagem apresentadas pela sua filha, como por exemplo: "A (nome da aluna) está fraca nas matérias de estudo. Precisa estudar mais" (CADERNO DE PROVAS, 1958).

Conforme destaca Chartier (2002, 2007), o caderno se constituía em um elo material entre a família e a escola, ele era o meio pelo qual os pais conheciam o aprendizado dos seus filhos, o trabalho dos/as professores/as, nomeadamente, se eles corrigiam os exercícios com regularidade, se os comentários eram afáveis ou ríspidos, quais os conteúdos valorizados, além de outras questões. Pelos cadernos que circulavam entre a família e a escola, os pais podiam compreender a situação do ensino em causa e se ele correspondia ao que esperavam dele.

\section{Consideraçõos}

Os cadernos analisados são produto de uma cultura escolar específica que se cumpre no quadro de uma instituição transnacional e no âmbito civilizacional ocidental. Eles nos colocam perante atividades de uma aluna de uma escola confessional em Santa Catarina (Brasil) em meados do século XX, permitindo ver o quanto elas se inscrevem numa dinâmica pedagógica que se insere no processo de consolidação da modernidade, ainda que nem sempre prosseguindo a linearidade dos modelos educativos mais propalados. O conjunto dos cadernos nos dá informação preciosa sobre o ensino/aprendizagem que tinham as alunas de uma escola de freiras salesianas, mas tal não é suficiente para entrarmos plenamente na caixa preta da sala de aula e alcançarmos diretamente a complexidade das interações que nesta se estabeleceu num espaço/tempo muito concreto.

Se os cadernos se constituem em uma importante fonte para o estudo histórico da escola ao permitirem desvelar práticas educativas de períodos e espaços bem delimitados, porque eles são precisamente artefatos escolares dos/as alunos/as, já que resultam do registro de atividades que são relevantes (GVIRTZ E LARRONDO, 2008) para aquela cultura em que se inscrevem; só um exercício interpretativo arqueológico poderá conduzir a compreensões mais profundas que integrem, por exemplo, a exigência, a 
disciplina, as relações, os ritmos. Não há dúvida que os cadernos são lacunares sobre vários aspectos da atividade escolar, oferecendo muitas vezes apenas elementos que indiciam práticas de ensino/aprendizagem.

Assim sendo, importa submeter esses materiais a análises de tipos e níveis diferentes, partindo da informação mais opulenta até aos indícios menos evidentes. Reconhecemos que, sendo fontes importantes para a compreensão do ensino/aprendizagem, os cadernos apresentam limitações, principalmente, quando o que se quer analisar são práticas dos alunos que tendem a escapar ao universo da escrita. Mesmo que se esteja perante uma primeira abordagem, como a que aqui fazemos, a interpretação não pode descurar informação proveniente de outras fontes e o contexto em que os cadernos foram produzidos.

Neste trabalho incidimos sobre um conjunto de 25 cadernos pertencentes a uma aluna que cursou o ensino primário, numa cidade do interior de Santa Catarina, na segunda metade da década de cinquenta do século $X X$, sendo, mais precisamente, produto de um ensino da responsabilidade das Irmãs Salesianas da Congregação das Filhas de Maria Auxiliadora que visava, sobretudo, oferecer uma formação escolar cristã a meninas da região. O que fica nítido é que o ensino dos princípios religiosos era o eixo central da educação ministrada naquele colégio. As anotações feitas nos cadernos do $4^{\circ}$ ano revelam que foram indicadas cerca de 80 tarefas de Religião naquele ano. A maioria delas indicava o número das páginas do Catecismo a serem estudadas ${ }^{9}$. Supõe-se que este conhecimento era cobrado principalmente por meio de arguição oral, pois foram relativamente poucas as tarefas realizadas por escrito.

Ainda outras tarefas eram cobradas por meio de ditados ou cópias sobre temas que poderiam incluir: Os Segredos de Deus, Pai Nosso, Glória ao Pai, Ave Maria, Salve Rainha, Mandamentos de Deus e da Igreja e os Sacramentos, Os Principais Misterios da Fé, além de outros. Sem dúvida, a doutrina da Igreja Católica era um dos conhecimentos mais exigidos dentre todos os que compunham o currículo escolar e isso estava muito alinhado com a matriz religiosa do colégio frequentado pela aluna que realizou os exercícios escritos aqui em análise.

\footnotetext{
${ }^{9}$ Destaque-se que havia um livro de Catecismo especifico para cada ano do ensino primário.
} 
Tudo indica que o ensino do colégio das freiras salesianas adotava uma didática orientada pela eficácia da repetição. Apesar de adotarem o Método Analítico na alfabetização, ele só era aplicado em parte; o livro base para o segundo ano estava alicerçado nos princípios da Escola Nova, porém a professora parece não ter captado seu "espírito" e seguia uma dinâmica pedagógica passando lições de cópias e ditados repetitivamente. As atividades registradas nos cadernos do terceiro e quarto anos revelam ainda de forma mais acentuada esse aspecto. Pode-se concluir que a finalidade do ensino ali registrado era a de propiciar o domínio da linguagem oral e escrita, os conhecimentos de aritmética e a aquisição de noções de História, Geografia e de Conhecimentos Gerais, conforme recomendado pela legislação. Se podemos detectar alguma abertura pedagógica ela não altera significativamente a cultura escolar tradicional. Mais do que a compreensão, parece prevalecer a memorização. A dinâmica pedagógica que transparece nos cadernos aqui analisados corresponde às questões vivenciadas pela sociedade brasileira dos anos cinquenta do século XX.

No período, o Brasil passava por processos de industrialização e de urbanização acelerados que estavam a exigir mais escolarização e inovações educacionais para atender às demandas do comércio e da indústria. No campo educacional, as lutas ideológicas foram travadas por posturas chamadas de conservadoras, representadas por setores ligados ao ensino particular, em especial às escolas confessionais e uma postura considerada inovadora representada por setores da chamada Escola Nova que defendiam a escola pública e estatal. Na realidade, a escola primária, tanto a pública quanto a particular, mantinha uma organização curricular tradicional, forjada em meados da década de 40, apesar das inúmeras proposições de modernização do ensino primário ocorridas na década de 50.

O aprofundamento de abordagem arqueológica desses cadernos pode permitir ilações mais consequentes e compreensivas das lógicas que sustentavam a pedagogia da escola que enquadrou a produção da escrita, alvo de análise neste trabalho. Aqui esboçamos um olhar geral procurando ver nos registros feitos nas páginas desses cadernos, aspectos que permitam alcançar o que era o ensino/aprendizagem numa escola que seguramente tendia a corresponder a projeções educativas das famílias da sociedade em que se integrava. 
Ainda que não seja possível generalizar somente a partir desses cadernos e dessa abordagem, parece ser claro que os exercícios registrados colocam-nos perante práticas pedagógicas do ensino primário de meados do século $X X$, no Brasil, e que visavam a aquisição de conhecimentos que possibilitassem o ingresso em um curso secundário ou no mundo do trabalho, atuando em profissões que não exigissem muito mais do que possuir o domínio de leitura e escrita e de matemática condizente com o utilizado em estabelecimentos comerciais da época. As práticas educativas desse período foram marcadas por um certo imobilismo pedagógico que dava singularidade ao período, envolto em muitos debates pedagógicos mas sem que algo de inovador se efetivasse na prática.

\section{Referências}

BRASIL. Decreto - lei nº 8.529 de 2 de janeiro de 1946, Lei Orgânica do Ensino Primário.

Coleção de Leis do Brasil, 1946. Rio de Janeiro: vol. 1. p. 640.

CADERNO de Classe (I), 1955. Manuscrito.

CADERNO de Classe (II), 1955. Manuscrito.

CADERNO de Classe (III), 1955. Manuscrito.

CADERNO de Classe do primeiro semestre de 1955. Manuscrito.

CADERNO de Classe do segundo semestre de 1955. Manuscrito.

CADERNO de Rascunho do ano de 1956. Manuscrito.

CADERNO de Exercícios do ano de 1956. Manuscrito. 
CADERNO de Caligrafia do terceiro ano primário. 1957. Manuscrito.

CADERNO a Limpo de 1957. Manuscrito.

CADERNO de Provas (1) do ano de 1958. Manuscrito.

CADERNO de Provas (2) do ano de 1958. Manuscrito.

CHARTIER, Anne Marie. Um dispositivo sem autor: cadernos e fichários na escola primária. Revista Brasileira de História da Educação, Campinas: n 3, Jan/Jun.2002.

CHARTIER, Anne Marie. Práticas de leitura e escrita. História e atualidade. Belo Horizonte: Autêntica, 2007.

FERNANDES, Rogério. Um marco no território da criança: o caderno escolar. In: MIGNOT, Ana Chrystina Venâncio (org.). Cadernos à vista: escola, memória e cultura escrita. Rio de Janeiro: EdUERJ, 2008.

FERREIRA, António Gomes. A difusão da escola e a afirmação da sociedade burguesa. In: Revista Brasileira de História da Educação. Campinas: n. 9. Jan/Jun., 2005.

FERREIRA, António Gomes; VECHIA, Ariclê. Le Project politique nationaliste brésilien et les cahiers scolaires des années 1930. In: MEDA,J.; MONTINO,D.; SANI, R. (orgs). School Exercise Books: a Complex Source for a History of the Approach to Schooling and Education in the 19th and 20th Centuries. Firenzi: Edizioni Polistampa, 2010.

GRISI, Rafael. O ensino da Leitura: o método e a cartilha. In: Revista Brasileira de Estudos Pedagógicos. Rio de Janeiro: n. 43. v. 16. jul/set, 1951.

GVIRTZ, Silvina; LARRONDO, Marina. Os cadernos de classe como uma fonte primária de pesquisa: alcances e limites teóricos e metodológicos para sua abordagem. In: MIGNOT, Ana Chrystina Venâncio (org.). Cadernos à vista: escola, memória e cultura escrita. Rio de Janeiro: EdUERJ, 2008.

LOPES, Isa Cristina da Rocha. Cadernos escolares: memória e discurso em marcas de correção. In: MIGNOT, Ana Chrystina Venâncio (org.). Cadernos à vista: escola, memória e cultura escrita. Rio de Janeiro: EdUERJ. 2008.

RIOS, Diogo Franco; FISCHER, Maria Cecília B. Cadernos de Beatriz: discussões teóricas para uma aproximação com a matemática nos registros de estágio da normalista gaúcha (1967). Revista de História da Educação Matemática. São Paulo: ano 3, nº 1,2017, p.168182.

RICCHETTI, Henrique. Infância. São Paulo: Cia Editora Nacional. 1952.

SANTA CATARINA. Decreto $\mathbf{n}^{\circ} 298$ de 13 de novembro de 1946, que estabeleceu a Lei Organica do Ensino Primário do Estado de Santa Catarina. 
SANTA CATARINA. Decreto $\mathbf{n}^{\circ} \mathbf{3 . 7 3 5}$ de 17 de dezembro de 1946, que estabelece o Regulamento para os Estabelecimentos de Ensino Primario do Estado de Santa Catarina.

SANTOS, Anabela Almeida da Costa; SOUZA, Marilene Proença Rebello. Cadernos Escoalres: como e o que se registra no contexto escolar? Revista Psicologia Escolar e Educacional. São Paulo: vol.9, n² 2. 2005. p. 291 -302.

TEIVE, Gladys Ghizoni; CUNHA, Maria Teresa. Circulação de princípios da Escola Nova no ensino da leitura e nos livros escolares de Santa Catarina (1930-1950). In: SOUZA, R. F. de; PINHEIRO, A. C. e LOPES, A. C. História da Escola Primária no Brasil. Investigação em perspectiva comparada em âmbito nacional. Aracaju: EDISE, 2015.

VECHIA, Ariclê; FERREIRA, António Gomes. A educação das crianças de ascendência alemã durante o Estado Novo: amainando as desigualdades? In: VECHIA, A.; FERREIRA, A. (orgs.). A criança e a escolarização: igualdade e desigualdade no espaço latinoamericano nos séculos XIX e XX. Curitiba: UTP, 2016.

VIÑAO, Antonio. Os cadernos escolares como fonte histórica: aspectos metodológicos e historiográficos. In: MIGNOT, Ana Chrystina V. (org.). Cadernos à vista: escola, memoria e cultura escrita. Rio de Janeiro: EDUERJ, 2008. 